\title{
Rapid assessment of wood traits for large-scale breeding selection in Picea mariana [Mill.] B.S.P.
}

\author{
Mireille Desponts $^{1} \cdot$ Martin Perron $^{1} \cdot$ Josianne DeBlois $^{1}$
}

Received: 4 November 2016 / Accepted: 16 May 2017 /Published online: 3 July 2017

(C) INRA and Springer-Verlag France 2017

\begin{abstract}
- Key message Pilodyn and acoustic velocity measurements on standing trees, used for predicting density and stiffness, can be good genetic selection tools for black spruce. Genetic parameters and selection efficiency were conserved in two breeding zones with contrasted bioclimatic conditions.

- Context Given the recent progress made in the black spruce genetic improvement program, the integration of juvenile wood mechanical properties as selection criteria is increasingly relevant.

- Aims This study aims to estimate the genetic parameters of in situ wood density and modulus of elasticity (MoE)

\section{Handling Editor: Ricardo Alia}

Contribution of co-authors M. Desponts is in charge of the black spruce breeding program. She contributed to the design of field data collection and the writing of the manuscript.

M. Perron contributed to the design of the project, statistical analysis, and the writing of the manuscript. J. DeBlois conducted statistical and resistograph data analysis and contributed to the writing of the manuscript.
\end{abstract}

Electronic supplementary material The online version of this article (doi:10.1007/s13595-017-0646-x) contains supplementary material, which is available to authorized users.

Mireille Desponts

mireille.desponts@mffp.gouv.qc.ca

Martin Perron

martin.perron@mffp.gouv.qc.ca

Josianne DeBlois

josianne.deblois@mffp.gouv.qc.ca

1 Ministère des Forêts, de la Faune et des Parcs, Direction de la recherche forestière, 2700 rue Einstein, Québec, Qc G1P 3W8, Canada measurements and to verify the efficiency of various measuring methods used for large-scale selection of black spruce based on wood quality.

- Methods Height, diameter, wood density, and some indirect measures of density (penetration and drilling resistance) and MoE (acoustical velocity and Pilodyn) were estimated on 2400 24-year-old trees of 120 open-pollinated families in progeny trials located in the continuous boreal or mixed forest subzones.

- Results Heritability of growth, density, and indirect density measurements varied from low to moderate and was moderate for acoustical velocity in both vegetation subzones. Expected genetic gains for wood properties based on in situ methods were higher for MoE proxy estimation combining Pilodyn and acoustic velocity.

- Conclusion Acoustic velocity is a good predictor of MoE. It is virtually unaffected by the environment and can be used on a large scale in the same manner as the Pilodyn for density. Using a proxy estimation that combines both methods helps optimize genetic gain for MoE.

Keywords Density · Modulus of elasticity · Field evaluation · Black spruce $\cdot$ Genetic

\section{Introduction}

Black spruce (Picea mariana [Mill.] B.S.P.) is a widely distributed conifer in the North American boreal forest. It colonizes a wide range of habitats and is known for its very high phenotypic plasticity. This species is of great economic importance to the Canadian forest industry, since its high-quality fiber and dense wood are desirable traits for paper and lumber production (Zhang and Koubaa 2008). 
Although characterized by slow growth, black spruce is the most planted tree species in Eastern Canada (Canadian Council of Forest Ministers 2015). In Quebec, the first improved generation was completed between 2000 and 2010 (Desponts and Numainville 2013). The improvement program covers a vast territory and several bioclimatic domains; it includes 5 breeding zones and over 5700 open-pollinated families collected on plus-trees adapted to specific ecological, climatic, and pedological conditions.

To date, improvement efforts have been primarily directed at growth, tree shape, and the creation of distinct breeding populations adapted to the province's various bioclimatic conditions. To maintain and standardize value-related lumber traits, wood properties must become a selection priority. Indeed, faster growth often negatively affects wood density and mechanical properties, by increasing the proportion of juvenile wood in stems, among other things (e.g., Dungey et al. 2006, Bouffier et al. 2009). Studies on black spruce have reported a negative correlation between growth rate and wood density (e.g., Zhang and Morgenstern 1995, Koubaa et al. 2000, Weng et al. 2011), but this trend has proven to be of little biological significance and inconsistent across plantation sites. Wood density is under moderate genetic control and presents weak genotype $\times$ environment $(\mathrm{G} \times \mathrm{E})$ interactions (e.g., Perron et al. 2013). To date, for this species, little is known about the genetic control of the most important mechanical properties for improving wood quality, namely, modulus of elasticity (MoE, or stiffness), modulus of rupture (MoR), and microfibril angle (MFA). Density and MoE can both be assessed quickly and non-destructively on-site and are closely related to MFA, which is linked to the quality of structural timber (e.g., Apiolaza 2009). High density is associated with greater amounts of wood per volume and stiffer stems, while MoE is closely associated with MFA, which largely determines wood stiffness. Black spruce MFA is much greater in juvenile than in mature wood (Alteyrac et al. 2006). This finding makes it even more relevant to improve wood properties at the juvenile stage, since a greater proportion of juvenile wood in plantation-produced lumber can be reached in the future, by reducing MFA and its variability (Apiolaza et al. 2013).

Selections targeting both wood quality and growth require monitoring and on-site measurements of thousands of individuals. Standard laboratory analyses are costly and destructive. To increase cost-efficiency and preserve the populations, several techniques for a fast, non-destructive in situ assessment of a range of wood traits have been tried, with more or less success. Pilodyn measurements were proved adequate to assess wood density (Kennedy et al. 2013, Chen et al. 2015), but they are not precise enough to be used alone to make selections. Indeed, only the outer 2 to $3 \mathrm{~cm}$ of the trunk is tested, and bark thickness variations may yield biased results for some species. A more recent technique involves estimating density by measuring wood resistance with a microdrill, using a Resistograph ${ }^{\circledR}$ (Isik and Li 2003, Bouffier et al. 2008, Eckard et al. 2010). The Resistograph ${ }^{\circledR}$ allows the measurement of the resistance amplitude for each individual growth ring. Unfortunately, its sensitivity to humidity and temperature (Eckard et al. 2010, Ukrainetz and O'Neill 2010) can affect results significantly. The interest of this method remains to be verified for species, such as black spruce, which have particularly dense and uniform wood within a growth ring. The static MoE can be estimated indirectly by measuring the velocity of acoustic propagation and the dynamic MoE. This technique generally yields good results, with moderate to high heritability values in plantations for several species (Johnson and Gartner 2006, Kumar and Burdon 2010, Kennedy et al. 2013, Lenz et al. 2013).

The first objective of this study was to estimate the genetic parameters including genetic variability, heritability, $\mathrm{G} \times \mathrm{E}$ interaction, and phenotypical and genetic correlations, as well as relative expected genetic gain, for wood density and MoE sampled on standing black spruce trees, in 4 open-pollinated progeny trials located in 2 contrasting vegetation subzones. Its second objective was to compare the efficiency of in situ, nondestructive methods (Pilodyn and Resistograph ${ }^{\circledR}$ ) of estimating wood density and the acoustic velocity for MoE, by validating them with laboratory measurements (X-ray densitometry and ultrasonic wave propagation velocity on wood samples). In the end, we discuss the use of these techniques for large-scale selection in a mixed and boreal forest environment and their potential integration into Quebec's black spruce genetic improvement program.

\section{Material and methods}

\subsection{Data collection}

The study focused on two distinct breeding populations representing two breeding zones located in different vegetation subzones (Saucier et al. 2003). The first breeding zone is located south of the St. Lawrence River, in the mixed forest vegetation subzone (hereafter referred to as "mixed forest"), on sedimentary bedrock composed mainly of limestone, shale, and sandstone. The second breeding zone is located on the north shore of the St. Lawrence River, in the continuous boreal forest subzone (hereafter referred to as "boreal forest"), on the Canadian Shield in the Laurentides Mountains, composed of bedrock of crystalline rock and more acid soils. In each vegetation subzone, 2 trials were established using the same halfsib families from regional sources, according to a randomized complete block design with 12 blocks and 4-tree linear plots for each family.

Trials of different subzones comprised different provenances from their respective subzone. In the mixed forest, 
the Neigette and Lac-Bellefontaine trials are composed of 275 open-pollinated families collected from plus-tree in 20 natural stands. Trials are located in the sugar maple-yellow birch bioclimatic domain, at altitudes of approximately $216 \mathrm{~m}$ and $427 \mathrm{~m}$, respectively (Table 1). Climatic conditions are milder at the Neigette site (mean annual temperature $2.9^{\circ} \mathrm{C}$; growth period 162.1 days) than at the Lac Bellefontaine (mean annual temperature $1.9{ }^{\circ} \mathrm{C}$; growth period 148.5 days).

In the boreal forest, the Plessis and Rivière-Chicoutimi trials are composed of 324 open-pollinated families collected from plus-tree in 15 natural stands. Trials are located in the balsam fir-white birch bioclimatic domain, at altitudes of 256 and $428 \mathrm{~m}$, respectively (Table 1). Climatic conditions at the Rivière-Chicoutimi site are colder (mean annual temperature $1.5^{\circ} \mathrm{C}$; growth period 139.8 days) than at the Plessis site (mean annual temperature $2.2{ }^{\circ} \mathrm{C}$; growth period 152.1 days) (Table 1).

At 24 years, trees were measured in September and October 2009 (mixed forest) and 2010 (boreal forest). With the exception of the Plessis trial, the plantations had been thinned mechanically in 2003 and 2004 by removing 1 of every 2 trees; the remaining individuals were then pruned.

In each vegetation subzone, 60 families were selected on the basis of their mean height growth relative to previous measurements taken at 10 to 11 years (30 superior families and 30 families with a mean growth similar to the trial mean). Ten trees were sampled per family and per trial, for a total of 1200 individuals per subzone. On-site, 1 tree per block from each family was selected mostly in the first 10 blocks, based on trunk size $(\mathrm{DBH} \geq 8.0 \mathrm{~cm}$, to allow for wood traits measurements) and good straightness. Tree height (TH) and diameter at breast height (DBH, at $1.3 \mathrm{~m})$ were measured. One 12$\mathrm{mm}$ pith-to-bark wood core was collected at the same height on each tree. Samples were kept in individual plastic bottles and frozen until used in the laboratory.

Pilodyn-measured wood density $\left(W D_{\text {pil }}\right)$ was assessed by shooting a blunt steel pin into the tree with constant pressure. Penetration depth was measured 3 to 5 times per tree, at a height of $1.3 \mathrm{~m}$, until 3 identical measurements (at a precision of $1.0 \mathrm{~mm}$ ) were obtained. Relative density $\left(W D_{\text {res }}\right)$ was also assessed by measuring the amplitude of micro-drilling resistance using an IML Resistograph® F400-S, from pith to bark, at the same height. When the drill inserts into the trunk of the tree, the device converts torque variations resulting from variations in wood resistance into relative density.

Three time-of-flight readings were taken using the Fakopp TreeSonic $₫$ microsecond timer (Fakopp Enterprise, Agfalva, Hungary) to derive the dynamic modulus of elasticity estimate, or $\mathrm{MoE}_{f a k+p i l}$. Probes were installed lengthwise on the tree trunks, $1 \mathrm{~m}$ apart, on each side of the sampling point, at a height of $1.3 \mathrm{~m}$. Using the average value of acoustic measurements converted into velocity $\left(V_{f a k}\right)$ and average Pilodyn readings, $M o E_{f a k+p i l}$ was calculated for each tree based on the equation described by Chen et al. (2015):

$M o E_{f a k+p i l}=\left(\frac{1}{W D_{p i l}}\right) \cdot 10000 V_{f a k}^{2}$

where $W D_{\text {pil }}$ is the average Pilodyn penetration depth (mm) and $V_{f a k}$ is the velocity of the stress wave as it penetrates the wood $\left(\mathrm{km} \mathrm{s}^{-1}\right)$.

\subsection{Laboratory measurements}

Wood samples were analyzed at Laval University (Québec, Canada). After thawing, cores were air-dried in a temperature and humidity-controlled chamber until they reached a stable $12 \%$ relative humidity. Volumetric wood density $\left(W D_{v o l}\right)$ was then measured on all samples using the length $l(\mathrm{~m})$ and the radius of cores $(r=0.006 \mathrm{~m})$ following:

$W D_{v o l}=l \cdot \Pi r^{2}$

A subsample of 240 cores was then selected among sampled stands (one randomly chosen core per family, for a total of 60 cores per trial). After smoothing out the sides of the cores, longitudinal ultrasonic wave propagation velocity $\left(V_{u l t r}\right)$ (broadband with a central frequency of $1 \mathrm{MHz}$ ) was measured based on the methodology described by Yang and Fortin (2005). Three time-of-flight readings were taken on each sample: at $1 \mathrm{~cm}$ from the bark, at maximum amplitude, and when the oscilloscope displayed a well-defined pulse onset. To take into account elements of the experimental setup, such as the frequency of the ultrasonic transducers and sample size, velocity $(\mathrm{m} / \mathrm{s})$ was calculated based on the following formula:

$V_{u l t r}=\frac{d_{w}}{t_{w}-t_{d}}$

where $d_{w}$ is the wave traveling distance in the wood specimen $(\mathrm{m}), t_{w}$ is the wave propagation time through the wood specimen and the measuring circuit (s), and $t_{d}$ is the wave traveling time delay due to the coupling medium and electric circuit (s).

With this measurement, we calculated apparent longitudinal dynamic elasticity $\left(M o E_{u l t r}\right)$ using the following equation:

$M o E_{u l t r}=\rho \cdot V_{u l t r}^{2} \cdot 10^{-6}$

where $\rho$ is the basic wood density at $12 \%$ humidity $\left(W D_{X-}\right.$ ray in $\mathrm{kg} / \mathrm{m}^{3}$ ) and $V_{\text {ultr }}$ is the velocity (in $\mathrm{m} / \mathrm{s}$ ). This indirect assessment of static MoE appears accurate since, for instance, a determination coefficient of 0.85 between these two measured properties was found by Yang and Fortin (2005) for Pinus radiata.

Wood density $\left(W D_{X-\text { ray }}\right)$ (basic density) was measured by X-ray densitometry (QTRS-01X; Quintek 
Table 1 Location of progeny trials and description of the climate $^{\mathrm{a}}$ in their respective ecological districts

\begin{tabular}{|c|c|c|c|c|}
\hline \multirow{2}{*}{$\begin{array}{l}\text { Vegetation subzone } \\
\text { Progeny trial }\end{array}$} & \multicolumn{2}{|c|}{ Mixed forest } & \multicolumn{2}{|c|}{ Boreal forest } \\
\hline & Neigette & Lac-Bellefontaine & Plessis & Rivière-Chicoutimi \\
\hline Latitude $\left({ }^{\circ} \mathrm{N}\right)$ & $48^{\circ} 25^{\prime} 23^{\prime \prime}$ & $48^{\circ} 01^{\prime} 46^{\prime \prime}$ & $48^{\circ} 17^{\prime} 56^{\prime \prime}$ & $48^{\circ} 05^{\prime} 52^{\prime \prime}$ \\
\hline Longitude $\left({ }^{\circ} \mathrm{W}\right)$ & $68^{\circ} 16^{\prime} 48^{\prime \prime}$ & $68^{\circ} 05^{\prime} 02^{\prime \prime}$ & $71^{\circ} 28^{\prime} 23^{\prime \prime}$ & $71^{\circ} 29^{\prime} 38^{\prime \prime}$ \\
\hline Elevation (m) & 216 & 427 & 256 & 428 \\
\hline DD5 $\left({ }^{\circ} \mathrm{C}\right)$ & 1415.5 & 1400.6 & 1456.5 & 1302.0 \\
\hline MAP (mm) & 1035.0 & 1151.4 & 986.3 & 1069.5 \\
\hline $\operatorname{MAT}\left({ }^{\circ} \mathrm{C}\right)$ & 2.9 & 1.9 & 2.2 & 1.5 \\
\hline GSL (days) & 162.1 & 148.5 & 152.1 & 139.8 \\
\hline
\end{tabular}

$D D 5$ degree days above $5^{\circ} \mathrm{C}, M A P$ mean annual precipitation, MAT mean annual temperature, GSL growing season length.

${ }^{\text {a }}$ Source of data: Régnière and Saint-Amant (2008)
Measurement Systems Inc., USA) on 1.6-mm-thick slices cut tangentially from the cores with a twin blade pneumatic saw. Samples were scanned from pith to bark along the radial face at a resolution of $40 \mu \mathrm{m}$. The limits of the annual growth rings were determined as per Lenz et al. (2013). Wood attributes, yearly earlywood and latewood density, yearly earlywood and latewood thickness, and the proportion of latewood were determined as per Ukrainetz et al. (2008).

\subsection{Data analysis}

\subsubsection{Resistograph ${ }^{\circledR}$ data processing}

Drilling charts showed major distortions in resistance measurement (amplitude, in \%), possibly resulting from inflection during the stem's trajectory into the tree to a 4- to 5-cm drilling depth. Consequently, only the measurements of the last 9 years of growth were kept for each tree. Ultimately, we also excluded the current year's ring (2009 or 2010) from the analysis, because its validity was doubtful.

For each ring, the earlywood-latewood (E/L) transition point was determined using a 6th-order polynomial function and the approach described in Koubaa et al. (2002). Parameters estimated were wood density $\left(W D_{\text {res }}\right)$, earlywood and latewood densities $\left(E W D_{\text {res }}\right.$ and $\left.L W D_{\text {res }}\right)$, ring width $\left(R W_{\text {res }}\right)$, and earlywood and latewood ring widths $\left(E R W_{\text {res }}\right.$ and $\left.L R W_{\text {res }}\right)$.

The latewood proportion $\left(L W P_{\text {res }}\right)$ was then calculated as follows:

$L W P_{\text {res }}=L R W_{\text {res }} / R W_{\text {res }} \cdot 100$

The intra-ring density variation $\left(I D V_{\text {res }}\right)$ was determined using the following equation:
$I D V_{\text {res }}=\sqrt{\left(W D_{\text {res }}-E W D_{\text {res }}\right)^{2} \cdot\left(1-L W P_{\text {res }}\right)+\left(W D_{\text {res }}-L W D_{\text {res }}\right)^{2} \cdot L W P_{\text {res }}}$

\subsubsection{Model}

All variables were analyzed separately for each vegetation subzone using a linear mixed model. Site and block effects were considered fixed, whereas family effects and their interaction with sites were considered random.

Covariance parameters and their standard errors were estimated using residual (restricted) maximum likelihood (REML) with the SAS MIXED procedure (SAS Institute Inc. 2009, version 9.2). The Wald Z-test was used to determine whether variance estimates were significantly greater than 0 .

\subsubsection{Heritability}

Individual $\left(h_{\text {ind }}^{2}\right)$ and family $\left(h_{f a m}^{2}\right)$ heritabilities were calculated separately for each vegetation subzone, as follows:

$$
\begin{aligned}
& h_{\text {ind }}^{2}=\frac{4 \sigma_{F}^{2}}{\sigma_{F}^{2}+\sigma_{S^{*} F}^{2}+\sigma_{\varepsilon}^{2}} \\
& h_{f a m}^{2}=\frac{\sigma_{F}^{2}}{\sigma_{F}^{2}+\frac{\sigma_{S^{*} F}^{2}}{n_{s}}+\frac{\sigma_{\varepsilon}^{2}}{n_{s} \cdot n_{h b l}}}
\end{aligned}
$$

where $\sigma_{F}^{2}$ corresponds to the family variance, $\sigma_{S^{*} F}^{2}$ is the sitefamily variance, and $\sigma_{\varepsilon}^{2}$ represents the experimental error variance (between plots). Terms $n_{s}$ and $n_{h b l}$ are the number of sites and the harmonic mean of the number of blocks per site, respectively. Standard errors of heritabilities were estimated using the delta method, based on the Taylor series (Lynch and Walsh 1998). 


\subsubsection{Expected genetic gain}

For each breeding zone, expected genetic gains $\left(G_{1 \%}\right)$ were estimated for all measured traits using $h_{\text {ind }}^{2}$ (see above); the phenotypic standard deviation $\left(\sigma_{p}=\sqrt{\left(\sigma_{F}^{2}+\sigma_{S^{*} F}^{2}+\sigma_{\varepsilon}^{2}\right.}\right)$; and a selected proportion of $1 \%$ that corresponds to a selection intensity of $i=2.66$ for a large population, which means that the mean of the selected population is 2.66 phenotypic standard deviations greater than the mean of the whole population, following:

$G_{1 \%}=i \cdot h_{\text {ind }}^{2} \cdot \sigma_{p}$

This high intensity of selection corresponds to standard practice in Quebec's Picea mariana improvement program (Desponts and Numainville 2013). Furthermore, all trait means were used to express results as percentages in order to express expected genetic gains on a relative basis.

\subsubsection{Correlations}

Type A genetic correlations $\left(r_{A}\right)$ between traits $\mathrm{X}$ and $\mathrm{Y}$ measured on the same tree were calculated using a multivariate REML model, with the MIXED and IML procedures of SAS according to the method of Holland (2006) and the following equation:

$r_{A}=\frac{\sigma_{F}(X, Y)}{\sqrt{\sigma_{F}^{2}(X) \cdot \sigma_{F}^{2}(Y)}}$

where $\sigma_{F}(X, Y)$ represents the genetic covariance between traits $\mathrm{X}$ and $\mathrm{Y}$, whereas $\sigma_{F}^{2}(X)$ and $\sigma_{F}^{2}(Y)$ are the respective family variances of traits $\mathrm{X}$ and $\mathrm{Y}$.

Type B genetic correlations $\left(r_{B}\right)$ were calculated as follows:

$r_{B}=\frac{\sigma_{F}^{2}}{\sigma_{F}^{2}+\sigma_{S^{*} F}^{2}}$

Finally, the phenotypic correlations $\left(r_{p}\right)$ between traits $\mathrm{X}$ and $\mathrm{Y}$ were calculated using the following equation, where covariance and variance estimates were obtained from a multivariate REML analysis with the MIXED and IML procedures of SAS according to the method of Holland (2006):

$r_{p}=\frac{\sigma_{F}(X, Y)+\sigma_{S^{*} F}(X, Y)+\sigma_{\varepsilon}(X, Y)}{\sqrt{\left(\sigma_{F}^{2}(X)+\sigma_{S^{*} F}^{2}(X)+\sigma_{\varepsilon}^{2}(X)\right) \cdot\left(\sigma_{F}^{2}(Y)+\sigma_{S^{*} F}^{2}(Y)+\sigma_{\varepsilon}^{2}(Y)\right)}}$

Standard errors of all these correlations were also calculated using the delta method.

\subsubsection{Laboratory wood trait measurements}

A Pearson correlation coefficient was calculated between each laboratory and field wood trait measurements to determine their relationship. To be more conservative, we used a significance level of 0.01 .

\section{Results}

\subsection{Descriptive statistics}

Overall, coefficients of variation were acceptable, with values ranging from 7 to $24 \%$, except for Resistograph ${ }^{\circledR}$ measurements, for which they sometimes exceeded $40 \%$ (Table S1). Trees in the mixed forest clearly grew faster than those in the boreal forest, as shown by their larger $\mathrm{DBH}(>150 \mathrm{~mm}$ in the mixed forest and $<120 \mathrm{~mm}$ in the boreal forest), greater $\mathrm{DBH} / \mathrm{TH}$ ratio, and wider rings $\left(R W_{\text {res }}\right)$. The mixed forest trials were also associated to lower values for all wood and intra-ring density traits, whether they were measured directly $\left(W D_{v o l}<476\right.$ and $>487 \mathrm{~kg} \mathrm{~m}^{-3}$ for the mixed and boreal forests, respectively) or indirectly $\left(W D_{p i l}\right.$ and, to a lesser extent, $W D_{\text {res }}$, $\left.E W D_{\text {res }}, L W D_{\text {res }}\right)$. The proportion of latewood $\left(L W P_{\text {res }}\right)$ was similar across trials. The $I D V_{\text {res }}$ index differed among subzones, but the very high coefficients of variation reflect a lack of accuracy for this variable. Differences among trials and subzones were much less apparent for modulus of elasticity traits, except that $M o E_{f a k+p i l}$ was slightly higher for the boreal forest (Table S1).

\subsection{Genetic parameters and relative expected genetic gains of growth traits}

The relative magnitude of the among-family variance component for growth traits was much higher in the mixed forest $(2.4-13.3 \%)$ than in the boreal forest $(0$ $5.1 \%$ ) (Table S2). This was true especially for $R W_{\text {res }}$ (4.8 times higher in the mixed forest). Significant family effects $(\alpha=0.05)$ were observed for all growth traits except DBH (boreal forest) and $R W_{\text {res }}$. Heritability values for growth traits were low to moderate in the mixed forest ( $\left.h_{\text {ind }}^{2} 0.09-0.53 ; h_{\text {fam }}^{2} 0.28-0.74\right)$ and low in the boreal forest $\left(h_{\text {ind }}^{2} 0-0.20 ; h_{\text {fam }}^{2} 0-0.49\right)$ (Table S2). Weak $\mathrm{G} \times \mathrm{E}$ interactions were observed for growth measurements $\left(r_{B} ; 0.74-1\right)$ in both vegetation subzones, except for $R W_{\text {res }}$. For growth traits, relative expected genetic gains by retaining the top $1 \%$ were much greater in the mixed forest $(4.46-14.62 \%)$ than in the boreal forest $(0$ $5.58 \%$ ) (Table S2). 
3.3 Genetic parameters and relative expected genetic gains of wood traits

\subsubsection{Wood density}

The relative magnitude of the among-family variance component for the three wood density traits $\left(W D_{v o l}, W D_{p i l}, W D_{\text {res }}\right)$ varied differently between subzones but were sufficiently high to allow selection (3.6-8\%) (Table 2). The among-family variance components were significant for all wood density traits, except for $W D_{\text {res }}$ in the boreal forest. In the two vegetation subzones, individual heritability for density measurements was low (0.14-0.32). For family heritability, values were moderate, in particular for $W D_{\text {res }}(0.34-0.49)$, or high in the case of $W D_{v o l}(0.62)$ in the boreal forest. Heritability values for wood density traits were similar in both vegetation subzones, except for $W D_{\text {res }}$. In the two vegetation subzones, weak $\mathrm{G} \times \mathrm{E}$ interaction was found for density traits. For $W D_{v o l}$ and $W D_{\text {pil }}$, the relative expected genetic gains by selecting the best $1 \%$ were of the same magnitude for both vegetation subzones (4.65-5.70\%). However, for $W D_{r e s}$, gains in the mixed forest $(13.81 \%)$ were almost double those in the boreal forest (8.37\%; Table 2).

\subsubsection{Intra-ring density}

In the mixed forest, the among-family variance components were significant for $E W D_{\text {res }}$ and $L W D_{\text {res }}$, whereas in the boreal forest, this effect was significant only for $E W D_{\text {res }}$ (Table 3). The among-family variance was nil for $I D V_{\text {res }}$ in the two subzones and very weak to nil for $L W P_{\text {res }}$. The heritability values for $E W D_{\text {res }}$ and $L W D_{\text {res }}$ (Table 3 ) were similar to that of $W D_{\text {res }}$ (Table 2). The individual heritability values for intra-ring density measurements were low and very weak to nil for $I D V_{\text {res }}$ and $L W P_{\text {res }}$ in both subzones. Values for family heritability were higher and more variable among traits, with some values for $E W D_{\text {res }}$ and $L W D_{\text {res }}$ low in the boreal forest $(0.31-0.32)$ and moderate in the mixed forest $(0.44-0.54)$. All heritability values of the traits measured with the Resistograph ${ }^{\circledR}$ were lower in the boreal forest. There were weak $\mathrm{G} \times \mathrm{E}$ interactions $\left(r_{B} ; 0.68-1\right)$ for intra-ring measurements in the two vegetation subzones, and naturally, for traits with an among-family variance component of 0 . For $E W D_{\text {res }}$ and $L W D_{\text {res }}$, expected gains in the mixed forest $(12.58-13.42 \%)$ were almost double those in the boreal forest (7.22-7.82\%, Table 3), similar to mean wood density traits (see above). In both subzones, gains were nil for $I D V_{\text {res }}$ and very small to nil for $L W P_{\text {res. }}$.

\subsubsection{Modulus of elasticity}

The among-family variance component for modulus of elasticity traits appeared higher in terms of percentage than for other wood traits and particularly for $V_{\text {fak }}(13.3$ and $12.0 \%$ for the mixed and boreal forest, respectively, Table 4). The only other parameter showing a similarly high among-family variance proportion was $\mathrm{TH}$ in the mixed forest (Table S2). Values for $M o E_{f a k+p i l}$ are similar in both vegetation subzones (9.0 and 9.1\%). In both subzones, the among-family variance component was significant for $V_{f a k}$ and $M o E_{f a k+p i l}$. In the two subzones, individual heritabilities for $V_{f a k}$ and $M o E_{f a k+p i l}$ were similar and moderate (0.36-0.53; Table 4). Unlike growth traits, no trend is present between vegetation subzones for modulus of elasticity individual heritability. Family heritability (0.61-0.74) was high and, hence, greater than individual heritability, but it shows exactly the same trend. There were weak $\mathrm{G} \times \mathrm{E}$ interactions $\left(r_{B} ; 0.80-1\right)$ for these traits. In both subzones, expected gains for $M o E_{f a k+p i l}$ (19.64$20.17 \%$ ) were of the same magnitude and almost twice those for the $V_{\text {fak }}$ trait only (11.38-12.82\%; Table 4).

\subsection{Correlation between growth and wood traits}

\subsubsection{Phenotypic correlations}

Overall, in the two vegetation subzones, phenotypic correlations between growth, density $\left(W D_{v o l}\right)$, and density estimates $\left(W D_{p i l}\right.$ and $W D_{\text {res }}$ ) were relatively weak and negative (with the exception of $W D_{\text {pil }}$, of course) (Tables 5 and 6). Correlations between growth traits and $W D_{\text {res }}$ were the weakest. In both vegetation subzones, TH was positively correlated to $V_{f a k}$ and very weakly correlated to $M o E_{f a k+p i l}$, while DBH (for the mixed forest only since correlations were not appropriate for the boreal forest because of no significant additive effect), $\mathrm{DBH} / \mathrm{TH}$, and $R W_{\text {res }}$ were negatively correlated to these traits, yet with higher values.

\subsubsection{Genetic correlations}

In the mixed forest, growth parameters were all negatively correlated to density measurements (except for $W D_{\text {pil }}$ ), with values ranging from -0.55 and -0.03 and weaker correlations to the $\mathrm{DBH} / \mathrm{TH}$ ratio (Table 5). Correlations between growth measurements and $V_{f a k}$ and $M o E_{f a k+p i l}$ were weak overall. In the boreal forest, weak correlations were obtained between growth measurements, $W D_{v o l}$ and $W D_{r e s}$, with the exception of a very strong and negative correlation between the two Resistograph ${ }^{\circledR} R W_{\text {res }}$ and $W D_{\text {res }}$ measurements $(-0.78$, Table 6). The correlation between $W D_{p i l}$ and $\mathrm{TH}$ was moderate and positive $(0.45$, Table 6$)$. The correlation between $W D_{p i l}$ and $\mathrm{DBH} / \mathrm{TH}$ was also moderate, yet negative $(-0.43)$. This differentiated the two vegetation subzones, since the correlation for the mixed forest was 0.13 (Table 5). Results with $V_{f a k}$ and $M o E_{f a k+p i l}$ were comparable in both subzones, except for the stronger correlation between $R W_{\text {res }}$ and $V_{f a k}$ in the boreal forest $(-0.24$ vs 0.04$)$. 
Table 2 Across-trial estimates of variances, narrow-sense individual heritability, narrow-sense family heritability, type B genetic correlation, relative expected genetic gain by selecting the top $1 \%$, standard error (between parentheses), and relative magnitude ${ }^{\mathrm{a}}$ [between brackets, \%] for wood density traits estimated at year 24 from progeny trials in the mixed and boreal forests

\begin{tabular}{|c|c|c|c|c|c|c|}
\hline \multirow{2}{*}{$\begin{array}{l}\text { Vegetation subzone } \\
\text { Parameter }\end{array}$} & \multicolumn{3}{|c|}{ Mixed forest } & \multicolumn{3}{|c|}{ Boreal forest } \\
\hline & $W D_{v o l}$ & $W D_{\text {pil }}$ & $W D_{\text {res }}$ & $W D_{v o l}$ & $W D_{p i l}$ & $W D_{\text {res }}$ \\
\hline \multirow[t]{3}{*}{$\sigma_{F}^{2}$} & $78.45^{\mathrm{b}}$ & $0.28^{\mathrm{b}}$ & $1.37^{\mathrm{b}}$ & $88.07^{\mathrm{b}}$ & $0.16^{\mathrm{b}}$ & 1.11 \\
\hline & $(24.45)$ & $(0.11)$ & $(0.57)$ & $(27.55)$ & $(0.06)$ & $(0.69)$ \\
\hline & [6.9] & {$[5.8]$} & {$[5.6]$} & {$[8.0]$} & {$[5.3]$} & {$[3.6]$} \\
\hline \multirow[t]{3}{*}{$\sigma_{S * F}^{2}$} & 0 & 0.07 & 0.51 & 3.93 & 0 & 0.38 \\
\hline & & $(0.10)$ & $(0.53)$ & (19.87) & & $(0.77)$ \\
\hline & {$[0]$} & {$[1.5]$} & {$[2.1]$} & {$[0.4]$} & {$[0]$} & {$[1.2]$} \\
\hline \multirow[t]{3}{*}{$\sigma_{\varepsilon}^{2}$} & $1062.20^{\mathrm{b}}$ & $4.42^{\mathrm{b}}$ & $22.43^{\mathrm{b}}$ & $1008.00^{\mathrm{b}}$ & $2.84^{\mathrm{b}}$ & $29.44^{\mathrm{b}}$ \\
\hline & $(45.31)$ & $(0.19)$ & $(0.98)$ & (43.99) & $(0.12)$ & (1.44) \\
\hline & {$[93.1]$} & {$[92.7]$} & {$[92.3]$} & [91.6] & [94.7] & [95.2] \\
\hline \multirow[t]{2}{*}{$h_{\text {ind }}^{2}$} & 0.28 & 0.23 & 0.23 & 0.32 & 0.21 & 0.14 \\
\hline & $(0.08)$ & $(0.09)$ & $(0.09)$ & $(0.09)$ & $(0.07)$ & $(0.09)$ \\
\hline \multirow[t]{2}{*}{$h_{f a m}^{2}$} & 0.59 & 0.52 & 0.49 & 0.62 & 0.52 & 0.34 \\
\hline & $(0.08)$ & $(0.13)$ & $(0.13)$ & $(0.10)$ & $(0.09)$ & $(0.16)$ \\
\hline \multirow[t]{2}{*}{$r_{B}$} & $1^{\mathrm{b}}$ & $0.80^{\mathrm{b}}$ & $0.73^{\mathrm{b}}$ & $0.96^{\mathrm{b}}$ & $1^{\mathrm{b}}$ & 0.74 \\
\hline & $(0)$ & $(0.26)$ & $(0.25)$ & $(0.21)$ & (0) & $(0.46)$ \\
\hline$G_{1 \%}$ & 5.32 & 5.50 & 13.81 & 5.70 & 4.65 & 8.37 \\
\hline
\end{tabular}

$\sigma_{F}^{2}$ Among-family variance component estimate, $\sigma_{S^{*} F}^{2}$ site $\times$ family interaction variance component estimate, $\sigma_{\varepsilon}^{2}$ residual variance estimate due to among-plot variation, $h_{\text {ind }}^{2}$ unbiased individual-tree narrow-sense heritability, $h_{\text {fam }}^{2}$ unbiased half-sib narrow-sense heritability, $r_{B}$ type B genetic correlation, $G_{1 \%}$ relative expected genetic gain by selecting the top $1 \%$ expressed as a percentage, $W D_{v o l}$ volumetric wood density, $W D_{p i l}$ Pilodyn wood density, $W D_{\text {res }}$ Resistograph ${ }^{\circledR}$ wood density

${ }^{a}$ Percentage of each estimated variance component to total (phenotypic) variance $\left(\sigma_{p}^{2}=\sigma_{F}^{2}+\sigma_{S^{*} F}^{2}+\sigma_{\varepsilon}^{2}\right)$

${ }^{\mathrm{b}}$ Significantly different from 0 (for $r_{B}$ ) or significantly positive (for variance estimates) at the $5 \%$ significance level.

\subsection{Correlation between field and laboratory wood trait measurements}

X-ray sample analysis indicated a cambial age at DBH ranging from 16 to 18 years (Table S3). Results of previous indirect measurements taken from the outermost tree rings were about 12 to 17 years. This age range corresponds to the end of the juvenile wood phase in black spruce (Koubaa et al. 2000, Alteyrac et al. 2006). Overall, laboratory measurements showed trends similar to those observed with field data (Table S3). Variation coefficients of laboratory measurements were lower than those of in situ measurements for all variables and, more particularly, for X-ray measurements.

In general, moderate yet significant correlations (40 to $75 \%$ in absolute value) were observed between in situ and laboratory measurements of density, acoustic wave propagation velocity, and calculated MoE (Table S4). However, except for $R W_{\text {res }}$, none of the measurements taken using the Resistograph ${ }^{\circledR}$ were significantly correlated to corresponding laboratory measurements.

\section{Discussion}

The study covered two distinct improvement populations in two regions with different bioclimatic conditions. As expected, the proportion of among-family variance for growth traits was considerably lower in the boreal forest than in the mixed forest. This indicates that site fertility effects were more important for growth traits. Analysis of the genetic parameters of wood properties indicates that among-family variances for $V_{f a k}$ and $M o E_{f a k+p i l}$ are of the same magnitude in both vegetation subzones. Likewise, for density measurements based on $W D_{v o l}$ and $W D_{\text {pil }}$, the proportion of among-family variance remained the same (and even increased in the boreal forest for $W D_{v o l}$ ).

Analysis of wood properties using the Resistograph $®$ does not seem appropriate for black spruce, probably because of the species' high wood density. Indeed, results were inconsistent among mixed and boreal forest subzones, and among-family variance estimates were low to nil for many traits measured with this tool. 
Table 3 Across-trial estimates of variances, narrow-sense individual heritability, narrow-sense family heritability, type B genetic correlation, relative expected genetic gain by selecting the top $1 \%$, standard error (between parentheses), and relative magnitude ${ }^{\mathrm{a}}$ [between brackets, $\%$ ] for intra-ring density traits estimated at year 24 from progeny trials in the mixed and boreal forests

\begin{tabular}{|c|c|c|c|c|c|c|c|c|}
\hline \multirow{2}{*}{$\begin{array}{l}\text { Vegetation subzone } \\
\text { Parameter }\end{array}$} & \multicolumn{4}{|c|}{ Mixed forest } & \multicolumn{4}{|c|}{ Boreal forest } \\
\hline & $E W D_{\text {res }}$ & $L W D_{\text {res }}$ & $I D V_{\text {res }}$ & $L W P_{\text {res }}$ & $E W D_{\text {res }}$ & $L W D_{\text {res }}$ & $I D V_{\text {res }}$ & $L W P_{\text {res }}$ \\
\hline \multirow[t]{3}{*}{$\sigma_{F}^{2}$} & $1.30^{\mathrm{b}}$ & $1.50^{\mathrm{b}}$ & 0 & 4.57E-05 & $0.99^{\mathrm{b}}$ & 1.14 & 0 & 0 \\
\hline & $(0.62)$ & $(0.52)$ & & (3.97E-05) & $(0.58)$ & $(0.76)$ & & \\
\hline & {$[4.7]$} & {$[5.6]$} & {$[0]$} & {$[1.4]$} & [2.9] & {$[3.2]$} & {$[0]$} & {$[0]$} \\
\hline \multirow[t]{3}{*}{$\sigma_{S^{*} F}^{2}$} & 0.61 & 0 & 0.007 & 0 & 0 & 0.31 & $0.025^{\mathrm{b}}$ & 0 \\
\hline & $(0.61)$ & & $(0.012)$ & & & $(0.88)$ & $(0.013)$ & \\
\hline & {$[2.2]$} & {$[0]$} & {$[0.9]$} & {$[0]$} & {$[0]$} & {$[0.9]$} & {$[4.2]$} & {$[0]$} \\
\hline \multirow{3}{*}{$\sigma_{\varepsilon}^{2}$} & $26.00^{\mathrm{b}}$ & $25.58^{\mathrm{b}}$ & $0.815^{\mathrm{b}}$ & $0.0033^{\mathrm{b}}$ & $33.63^{\mathrm{b}}$ & $34.08^{\mathrm{b}}$ & $0.565^{\mathrm{b}}$ & $0.0060^{\mathrm{b}}$ \\
\hline & (1.14) & (1.09) & $(0.036)$ & $(0.0001)$ & (1.60) & (1.68) & $(0.028)$ & $(0.0003)$ \\
\hline & [93.1] & [94.4] & [99.1] & [98.6] & {$[97.1]$} & [95.9] & {$[95.8]$} & {$[100]$} \\
\hline \multirow{2}{*}{$h_{\text {ind }}^{2}$} & 0.19 & 0.22 & 0 & 0.05 & 0.11 & 0.13 & 0 & 0 \\
\hline & $(0.09)$ & $(0.07)$ & & $(0.05)$ & $(0.07)$ & $(0.08)$ & & \\
\hline \multirow{2}{*}{$h_{f a m}^{2}$} & 0.44 & 0.54 & 0 & 0.21 & 0.31 & 0.32 & 0 & 0 \\
\hline & $(0.14)$ & $(0.09)$ & & $(0.15)$ & $(0.13)$ & $(0.17)$ & & \\
\hline \multirow[t]{2}{*}{$r_{B}$} & $0.68^{\mathrm{b}}$ & $1^{\mathrm{b}}$ & 0 & $1^{\mathrm{b}}$ & $1^{\mathrm{b}}$ & 0.79 & 0 & . \\
\hline & $(0.28)$ & (0) & & (0) & (0) & $(0.54)$ & & \\
\hline$G_{1 \%}$ & 13.42 & 12.58 & 0 & 1.76 & 7.22 & 7.82 & 0 & 0 \\
\hline
\end{tabular}

$E W D_{\text {res }}$ Resistograph $®$ earlywood density, $L W D_{\text {res }}$ Res. latewood density, $I D V_{\text {res }}$ Res. intra-ring density variation, $L W P_{\text {res }}$ Res. latewood proportion

${ }^{\text {a }}$ Percentage of each estimated variance component to total (phenotypic) variance $\left(\sigma_{p}^{2}=\sigma_{F}^{2}+\sigma_{S^{*} F}^{2}+\sigma_{\varepsilon}^{2}\right)$.

${ }^{\mathrm{b}}$ Significantly different from 0 (for $r_{B}$ ) or significantly positive (for variance estimates) at the $5 \%$ significance level. See Table 2 for parameter definitions.

Heritability estimates accounted for the same phenomenon for the effect of site fertility, with much lower estimated values in the boreal forest for all growth traits. The importance of microsite effects has already been reported for all first-generation progeny trials conducted in growth-restrictive environments, where microsite-level fertility variations can determine growth factors and increase within-plot variability to the point of significantly reducing selection efficiency (Desponts and Numainville 2013). However, estimates of all wood properties except Resistograph ${ }^{\circledR}$ measurements either remained the same across vegetation subzones or were higher in the boreal forest for $W D_{v o l}$ and $M o E_{f a k+}$ pil. As expected for black spruce, there were weak $\mathrm{G} \times \mathrm{E}$ interactions for wood traits in both subzones. These results agree with those of many other studies on conifers (Johnson and Gartner 2006, Chen et al. 2014, Ratcliffe et al. 2014).

Of greatest interest to tree breeders are the relatively weak phenotypic correlations between growth and acoustic measurements $\left(V_{f a k}\right.$ and $\left.M o E_{f a k+p i l}\right)$. As in most comparable studies on Picea species (Kennedy et al. 2013, Lenz et al. 2013, Chen et al. 2015), these two wood properties showed a negative phenotypic correlation with radial growth, along with a weaker, yet positive correlation with height. This was observed in both subzones. Genetic correlations between $V_{f a k}$ and $M o E_{f a k+p i l}$ and height or radial growth remained rather weak overall but were always positive in the case of height. Since the variability of the various parameters allowed the identification of superior quality trees based on several of these criteria during mass selection, it appears possible to improve trees simultaneously for these wood properties and growth traits.

As expected, phenotypic correlations between density and growth measurements were negative, with values ranging from weak to moderate. Surprisingly, however, genetic correlations between $\mathrm{TH}$ or the $\mathrm{DBH} / \mathrm{TH}$ ratio and density were clearly negative in the mixed forest, but positive in the boreal forest. This result might be due to very low and slightly variable radial growth observed in the boreal subzone, a phenomenon demonstrated by Johnson and Gartner (2006) for Douglas-fir. When DBH was held constant, these authors observed a positive correlation between height and density and concluded that radial growth was closely yet negatively linked to density. Considering the very slow radial growth of black spruce in the boreal forest, radial growth may be less determinant for wood density in this subzone.

Of particular relevance to tree breeders are also the relatively weak phenotypic correlations between the $V_{f a k}$ or $M o E_{f a k+p i l}$ measurements and all the density measurements. Indeed, equivalent genetic correlations between these two variables showed 
Table 4 Across-trial estimates of variances, narrow-sense individual heritability, narrow-sense family heritability, type B genetic correlation, relative expected genetic gain by selecting the top $1 \%$, standard error (between parentheses), and relative magnitude ${ }^{\mathrm{a}}$ [between brackets, \%] for modulus of elasticity estimated at year 24 from progeny trials in the mixed and boreal forests

\begin{tabular}{|c|c|c|c|c|}
\hline \multirow{2}{*}{$\begin{array}{l}\text { Vegetation subzone } \\
\text { Parameter }\end{array}$} & \multicolumn{2}{|c|}{ Mixed forest } & \multicolumn{2}{|c|}{ Boreal forest } \\
\hline & $V_{f a k}$ & $M o E_{f a k+p i l}$ & $V_{f a k}$ & $M o E_{f a k+p i l}$ \\
\hline \multirow[t]{3}{*}{$\sigma_{F}^{2}$} & $0.008^{\mathrm{b}}$ & $0.040^{\mathrm{b}}$ & $0.008^{\mathrm{b}}$ & $0.06^{\mathrm{b}}$ \\
\hline & $(0.002)$ & $(0.013)$ & $(0.002)$ & $(0.02)$ \\
\hline & {$[13.3]$} & {$[9.0]$} & {$[12.0]$} & {$[9.1]$} \\
\hline \multirow[t]{3}{*}{$\sigma_{S * F}^{2}$} & 0.0003 & 0.010 & 0 & 0 \\
\hline & $(0.0011)$ & $(0.009)$ & & \\
\hline & {$[0.5]$} & {$[2.3]$} & {$[0]$} & {$[0]$} \\
\hline \multirow[t]{3}{*}{$\sigma_{\varepsilon}^{2}$} & $0.054^{\mathrm{b}}$ & 0.393 & $0.058^{\mathrm{b}}$ & $0.60^{\mathrm{b}}$ \\
\hline & $(0.002)$ & $(0.017)$ & $(0.002)$ & $(0.03)$ \\
\hline & {$[86.2]$} & [88.7] & {$[88.0]$} & {$[90.9]$} \\
\hline \multirow[t]{2}{*}{$h_{\text {ind }}^{2}$} & 0.53 & 0.36 & 0.48 & 0.37 \\
\hline & $(0.12)$ & $(0.11)$ & $(0.11)$ & $(0.09)$ \\
\hline \multirow[t]{2}{*}{$h_{f a m}^{2}$} & 0.74 & 0.61 & 0.73 & 0.66 \\
\hline & $(0.07)$ & $(0.10)$ & $(0.05)$ & $(0.06)$ \\
\hline \multirow[t]{2}{*}{$r_{B}$} & $0.97^{\mathrm{b}}$ & $0.80^{\mathrm{b}}$ & $1^{\mathrm{b}}$ & $1^{\mathrm{b}}$ \\
\hline & $(0.12)$ & $(0.18)$ & $(0)$ & (0) \\
\hline$G_{1 \%}$ & 12.82 & 20.17 & 11.38 & 19.64 \\
\hline
\end{tabular}

$V_{f a k}$ Fakopp acoustic velocity, $M o E_{f a k+p i l}$ Fakopp and Pilodyn-derived modulus of elasticity

${ }^{\text {a }}$ Percentage of each estimated variance component to total (phenotypic) variance $\left(\sigma_{p}^{2}=\sigma_{F}^{2}+\sigma_{S^{*} F}^{2}+\sigma_{\varepsilon}^{2}\right)$

${ }^{\mathrm{b}}$ Significantly different from 0 (for $r_{B}$ ) or significantly positive (for variance estimates) at the $5 \%$ significance level. See Table 2 for parameter definitions.

almost nil phenotypic correlations with $W D_{\text {pil }}$ measurements. This finding indicates that the Pilodyn does not evaluate the same structural trait as acoustic velocity. This concurs with several other studies (Kennedy et al. 2013, Lenz et al. 2013). In contrast, we observed a much stronger genetic correlation between $V_{f a k}$ or $M o E_{f a k+p i l}$ and $W D_{v o l}$, but only in the boreal forest. This phenomenon can hardly be linked directly to very slow radial growth or to a variation in $\mathrm{DBH}$ but might be due to structural

Table 5 Phenotypic correlations (above the diagonal) and genetic correlations (below the diagonal) among growth and wood traits of trees from progeny trials in the mixed forest

\begin{tabular}{|c|c|c|c|c|c|c|c|c|c|c|c|c|}
\hline \multirow[t]{2}{*}{ Group of traits } & \multirow[b]{2}{*}{ Variable } & \multicolumn{4}{|c|}{ Growth } & \multicolumn{3}{|c|}{ Wood density } & \multicolumn{2}{|c|}{ Intra-ring density } & \multicolumn{2}{|c|}{ Modulus of elasticity } \\
\hline & & $\mathrm{TH}$ & $\mathrm{DBH}$ & $\mathrm{DBH} / \mathrm{TH}$ & $R W_{\text {res }}$ & $W D_{\text {vol }}$ & $W D_{\text {pil }}$ & $W D_{r e s}$ & $E W D_{\text {res }}$ & $L W D_{r e s}$ & $V_{f a k}$ & $M o E_{f a k+p i l}$ \\
\hline \multirow[t]{4}{*}{ Growth } & $\mathrm{TH}$ & & 0.59 & -0.15 & 0.18 & -0.21 & 0.19 & -0.17 & -0.18 & -0.11 & 0.12 & 0.02 \\
\hline & $\mathrm{DBH}$ & 0.69 & & 0.70 & 0.45 & -0.31 & 0.33 & -0.16 & -0.15 & -0.10 & -0.20 & -0.32 \\
\hline & DBH/TH & -0.18 & 0.59 & & 0.39 & -0.20 & 0.24 & -0.04 & -0.03 & -0.03 & -0.35 & -0.41 \\
\hline & $R W_{\text {res }}$ & 0.36 & 0.93 & 0.83 & & -0.26 & 0.11 & 0.03 & -0.01 & 0.08 & -0.26 & -0.27 \\
\hline \multirow[t]{3}{*}{ Wood density } & $W D_{v o l}$ & -0.40 & -0.52 & -0.23 & -0.40 & & -0.41 & 0.38 & 0.36 & 0.37 & 0.14 & 0.30 \\
\hline & $W D_{p i l}$ & 0.36 & 0.41 & 0.13 & 0.51 & -0.88 & & -0.49 & -0.44 & -0.47 & -0.02 & -0.46 \\
\hline & $W D_{\text {res }}$ & -0.39 & -0.36 & -0.03 & -0.55 & 0.96 & -0.95 & & 0.95 & 0.93 & -0.15 & 0.09 \\
\hline \multirow[t]{2}{*}{ Intra-ring density } & $E W D_{\text {res }}$ & -0.44 & -0.37 & 0.02 & -0.65 & 0.92 & -0.94 & 1.00 & & 0.91 & -0.18 & 0.05 \\
\hline & $L W D_{\text {res }}$ & -0.30 & -0.39 & -0.15 & -0.50 & 0.90 & -0.94 & 1.00 & 0.99 & & -0.14 & 0.09 \\
\hline \multirow[t]{2}{*}{ Modulus of elasticity } & $V_{f a k}$ & 0.29 & 0.10 & -0.18 & 0.04 & -0.10 & 0.32 & -0.36 & -0.44 & -0.24 & & 0.89 \\
\hline & $M o E_{f a k+p i l}$ & 0.19 & -0.03 & -0.24 & -0.12 & 0.19 & 0.03 & -0.07 & -0.16 & 0.07 & 0.96 & \\
\hline
\end{tabular}

$T H$ total height, $D B H$ diameter at breast height, $D B H / T H$ diameter-to-height ratio, $R W_{\text {res }}$ Resistograph ${ }^{\circledR}$ ring width, $W D_{v o l}$ volumetric wood density, $W D_{\text {pil }}$ Pilodyn wood density, $W D_{\text {res }}$ Resistograph ${ }^{\circledR}$ wood density, $E W D_{\text {res }}$ Res. earlywood density, $L W D_{\text {res }}$ Res. latewood density, $V_{\text {fak }}$ Fakopp acoustic velocity, $M o E_{f a k+p i l}$ Fakopp and Pilodyn-derived modulus of elasticity. 
Table 6 Phenotypic correlations (above the diagonal) and genetic correlations (below the diagonal) among growth and wood traits of trees from progeny trials in the boreal forest

\begin{tabular}{|c|c|c|c|c|c|c|c|c|c|c|c|}
\hline \multirow[t]{2}{*}{ Group of traits } & \multirow[b]{2}{*}{ Variable } & \multicolumn{3}{|c|}{ Growth } & \multicolumn{3}{|c|}{ Wood density } & \multicolumn{2}{|c|}{ Intra-ring density } & \multicolumn{2}{|c|}{ Modulus of elasticity } \\
\hline & & $\mathrm{TH}$ & $\mathrm{DBH} / \mathrm{TH}$ & $R W_{\text {res }}$ & $W D_{v o l}$ & $W D_{\text {pil }}$ & $W D_{\text {res }}$ & $E W D_{\text {res }}$ & $L W D_{\text {res }}$ & $V_{f a k}$ & $M o E_{f a k+p i l}$ \\
\hline \multirow[t]{3}{*}{ Growth } & $\mathrm{TH}$ & & -0.06 & 0.24 & -0.21 & 0.25 & -0.09 & -0.08 & -0.06 & 0.10 & -0.01 \\
\hline & $\mathrm{DBH} / \mathrm{TH}$ & -1.00 & & 0.44 & -0.29 & 0.32 & -0.07 & -0.07 & -0.06 & -0.36 & -0.44 \\
\hline & $R W_{\text {res }}$ & -0.27 & 0.72 & & -0.32 & 0.25 & -0.02 & -0.06 & 0.01 & -0.25 & -0.31 \\
\hline \multirow[t]{3}{*}{ Wood density } & $W D_{v o l}$ & 0.17 & 0.18 & . & & -0.44 & 0.30 & 0.27 & 0.27 & 0.22 & 0.37 \\
\hline & $W D_{p i l}$ & 0.45 & -0.43 & -0.02 & -0.70 & & -0.36 & -0.34 & -0.34 & -0.09 & -0.48 \\
\hline & $W D_{\text {res }}$ & 0.06 & 0.04 & -0.78 & 0.35 & -0.93 & & 0.95 & 0.94 & 0.08 & 0.21 \\
\hline \multirow[t]{2}{*}{ Intra-ring density } & $E W D_{\text {res }}$ & 0.14 & -0.10 & -1.00 & 0.24 & -1.00 & 0.99 & & 0.95 & 0.07 & 0.19 \\
\hline & $L W D_{\text {res }}$ & 0.17 & -0.06 & -1.00 & 0.30 & -1.00 & 1.00 & 1.00 & & 0.08 & 0.19 \\
\hline \multirow[t]{2}{*}{ Modulus of elasticity } & $V_{f a k}$ & 0.34 & -0.23 & -0.24 & 0.42 & 0.13 & 0.23 & 0.14 & 0.19 & & 0.91 \\
\hline & $M o E_{f a k+p i l}$ & 0.24 & -0.10 & -0.16 & 0.64 & -0.16 & 0.44 & 0.37 & 0.44 & 0.95 & \\
\hline
\end{tabular}

See Table 5 for the definition of trait abbreviations

peculiarities within the growth rings of slow-growing trees, as suggested by Lenz et al. (2013) for $P$. glauca.

In the present study, indirect rapid in situ measurements with Pilodyn, acoustic velocity, and $M o E_{f a k+p i l}$ were significantly correlated to corresponding laboratory measurements. These correlations allow their use as proxies for selections aiming to improve wood properties. Despite their limitations, indirect methods prove useful in large selection populations containing thousands of genotypes (up to 20,000 in one of Quebec's breeding zones for black spruce). We have also shown that Pilodyn and acoustic velocity measurements are reproducible across two contrasted vegetation subzones. This constitutes a great advantage when choosing selection methods for further improvement work, especially for a species, such as black spruce, which is distributed over a vast territory and under diverse bioclimatic conditions.

For these indirect rapid in situ measurements, the amongfamily variance and heritability observed in the present study and a scenario of selecting the top $1 \%$ lead to interesting expected relative genetic gains (4.65-20.17\%). The Pilodyn measurements of density yield more limited relative expected genetic gains (4.65-5.50\%), as compared to estimation of MoE acoustic velocity. Kennedy et al. (2013) also showed that the Pilodyn device alone could not effectively serve select for wood density in Sitka spruce. However, they found it useful to identify individuals or families with extreme density values. The use of $M o E_{f a k+p i l}$, obtained from the combined measurements of Pilodyn and Fakopp TreeSonic ${ }^{\circledR}$ devices appears as the most effective method to select for improved stem stiffness. Indeed, the combined measurements yielded relative expected genetic gains that were almost twice those of Fakopp TreeSonic ${ }^{\circledR}$ measurements alone, and they had positive genetic correlations with both height and wood density $\left(W D_{v o l}\right)$ in the two subzones. Similar results were also reported for Norway spruce by Chen et al. (2015), who obtained MoE (proxy estimation with Pilodyn and acoustic velocity) genetic gains of $18-19 \%$, based on breeding values and a $10 \%$ top-ranked fraction of the population.

Based on the results reported here, we have already integrated a rapid in situ method $\left(M o E_{f a k+p i l}\right)$ to improve wood stiffness in some of Quebec's black spruce deployment populations. We achieve this through genetic roguing or by recommending seed harvests only on top-ranked parents, according to operational needs and the productivity of the province's various clonal seed orchards. In parallel to the establishment of clonal seed orchards and breeding populations selected based on growth and form (Desponts and Numainville 2013) for a breeding zone, two black spruce clonal trials (approx. 20 ramets per clone per site) have been established using rooted cuttings. Approximately 10 ramets per trial were measured to identify the best $\left(M o E_{f a k+p i l}\right)$ parents in a breeding population. To reduce the sampling population for the next selected population, we now plan to do a multi-step selection at year 10 based on best linear unbiased prediction (BLUP) estimates, first by selecting for growth and adaptation traits, then by retaining the $30 \%$ top-ranking families. The remaining trees will be also evaluated for $M o E_{f a k+}$ pil. The final selection will then be based on a BLUP selection index. The weight of each trait will be determined using a graph simulation of various weights in order to maximize genetic gains for both traits according to White et al.'s (2007) suggestion (Box 15.12, p. 426).

\section{Conclusion}

Black spruce is a slow-growing species with a long juvenile tree growth period. Obviously, screening aimed at eliminating 
the families of the worst quality will be done first in young populations with juvenile wood or at the beginning of the transition from juvenile to mature wood. At this early stage, improving both density and MoE will effectively increase the future value of lumber, since these properties will continue to increase during the subsequent transition to mature wood. Rapid in situ measurements can help achieve important gains regarding these properties at a low cost and serve to identify families meeting a minimal standard in terms of growth, density, and mechanical wood properties.

This study clearly shows that Pilodyn and acoustic velocity traits are moderately heritable and have stable values in the two sampled vegetation subzones. Environmental conditions have little effect on the efficiency of selection for wood properties with these rapid in situ methods. The combination of these two methods $\left(M o E_{f a k+p i l}\right)$ appears to be the most appropriate approach for early, large-scale selection, allowing genetic gains for both wood density and stem stiffness. Selecting trees based on $M o E_{f a k+p i l}$ within a second step of a multi-step selection strategy could become more commonplace in large tree improvement programs, as it will support multi-trait selections that simultaneously target height growth, density, and MoE.

\begin{abstract}
Acknowledgements The work reported in this paper would have been impossible without the initial contribution of Michel Villeneuve (previously in charge of black spruce tree improvement program), all Ministry staff who participated in the establishment of progeny trials and collection of data (field and lab), particularly Gaétan Numainville and Jean-Noël Drouin. We sincerely thank the Wood Research Centre at Université Laval for allowing access to equipment and laboratory. The authors also wish to thank Yves Fortin and Alain Cloutier (currently leading the Renewable Materials Research Centre) for their technical support. Lastly, thanks to Aimée LeBreton, B.A., for her assistance in translating a previous version of the paper into English and Denise Tousignant for her thoughtful review.
\end{abstract}

\section{Compliance with ethical standards}

Funding This study was funded by the Ministère des Forêts, de la Faune et des Parcs du Québec as part of a project obtained by M. Desponts and M. Perron and integrated into the black spruce breeding program (M. Desponts).

\section{References}

Alteyrac J, Cloutier A, Ung CH, Zhang SY (2006) Mechanical properties in relation to selected wood characteristics of black spruce. Wood Fiber Sci 38:229-237

Apiolaza LA (2009) Very early selection for solid wood quality: screening for early winners. Ann For Sci 66:601

Apiolaza LA, Chauhan S, Hayes M, Nakada R, Sharma M, Walker J (2013) Selection and breeding for wood quality A new approach. N Z J For Sci 58:32-37

Bouffier L, Raffin A, Rosenberg P, Kremer A (2008) Can wood density be efficiently selected at early age in maritime pine (Pinus pinaster Ait)? Ann For Sci 65:1-8
Bouffier L, Raffin A, Rosenberg P, Meredieu C, Kremer A (2009) What are the consequences of growth selection on wood density in the French maritime pine breeding program. Tree Genet Genomes 5:1125

Canadian Council of Forest Ministers (2015) National Forestry Database Program http://nfdp.ccfm.org

Chen Z-Q, Garcia Gil MR, Karlsson B, Lundqvist S-O, Olsson L, Wu HX (2014) Inheritance of growth and solid wood quality traits in a large Norway spruce population tested at two locations in southern Sweden. Tree Genet Genomes 10:1291-1130

Chen Z-Q, Karlsson B, Lundqvist S-O, Garcia Gil MR, Olsson L, Wu HX (2015) Estimating solid wood properties using Pilodyn and acoustic velocity on standing trees of Norway spruce. Ann For Sci 72:499 508

Desponts M, Numainville G (2013) L'amélioration génétique de l'épinette noire au Québec: Bilan et perspective. Mémoire de recherche forestière No 169 Ministère des Ressources naturelles du Québec 29p

Dungey HS, Matheson AC, Kain D, Evans R (2006) Genetics of wood stiffness and its component traits in Pinus radiata. Can J For Res 36: $1165-1178$

Eckard JT, Isik F, Bullock B, Li B, Gumpertz M (2010) Selection efficiency for solid wood traits in Pinus taeda using time-of-flight acoustic and micro-drill resistance methods. For Sci 56:233-241

Holland JB (2006) Estimating genotypic correlations and their standard errors using multivariate restricted maximum likelihood estimation with SAS proc MIXED. Crop Science 46:642-654

Isik F, Li B (2003) Rapid assessment of wood density of live trees using the resistograph for selection in tree improvement programs. Can J For Res 38:2687-2696

Johnson GR, Gartner BL (2006) Genetic variation in basic density and modulus of elasticity of coastal Douglas-fir. Tree Genet Genomes 3: $25-33$

Kennedy SG, Cameron AD, Lee SJ (2013) Genetic relationships between wood quality traits and diameter growth of juvenile core wood in Sitka spruce. Can J For Res 43:1-6

Koubaa A, Zhang SY, Isabel N, Beaulieu J, Bousquet J (2000) Phenotypic correlations between juvenile-mature wood density and growth in black spruce. Wood Fiber Sci 32:61-71

Koubaa A, Zhang SY, Makni S (2002) Defining the transition from earlywood to latewood in black spruce based on intra-ring wood density profiles from X-ray densitometry. Ann For Sci 59:511-518

Kumar S, Burdon RD (2010) Genetic improvement of stiffness of radiata pine: synthesis of results from acoustic assessments. N Z J For Sci 40:185-197

Lenz P, Auty D, Achim A, Beaulieu J, Mackay J (2013) Genetic improvement of white spruce mechanical wood traits-Early screening by means of acoustic velocity. Forests 4:575-594

Lynch M, Walsh B (1998) Genetics and analysis of quantitative traits, Sinauer Associates, Inc, 980 p (Appendix 1, section Expectations and Variances of ratios, $\mathrm{p} 818$ )

Perron M, DeBlois J, Desponts M (2013) Use of resampling to assess optimal subgroup composition for estimating genetic parameters from progeny trials. Tree Genet Genomes 9:129-143

Ratcliffe B, Foster JH, Klapste J, Jaquish B, Mansfield SD, El-Kassaby YA (2014) Genetics of wood quality attributes in western larch. Ann For Sci 71:415-424

Régnière J, Saint-Amant R (2008) BioSIM 9, User's manual Natural Resources Canada, Canadian Forest Service, Information Report LAU-X-134F. $76 \mathrm{p}$

SAS Institute Inc (2009) SAS/STAT® 9.2 User's guide, Second edn. SAS Institute Inc., Cary

Saucier J-P, Grondin, P, Robitaille A, Bergeron, J-F (2003) Vegetation zones and bioclimatic domains in Québec Government of Quebec, ministère des Ressources naturelles, Direction des inventaires 
forestiers Diffusion code: 2003-3016 [http://mern.gouv.qc.ca/ publications/forest/publications/zone-a.pdf]

Ukrainetz NK, Kang K-Y, Aitken SN, Stoehr M, Mansfield SD (2008)

Heritability phenotypic and genetic correlations of coastal Douglasfir (Pseudotsuga menziesii) wood quality traits. Can J For Res 38: $1536-1546$

Ukrainetz NK, O’Neill GA (2010) An analysis of sensitivity contributing measurement error to Resistograph values. Can J For Res 40:806811

Weng YH, Tosh KJ, Fullarton MS (2011) Effects of height-growth selection on wood density in black spruce in New Brunswick, Canada. For Chron 87:116-121
White TL, Adams WT, Neale DB (2007) Forest genetics CABI Wallingford

Yang J-L, Fortin Y (2005) Evaluating strength properties of Pinus radiata from ultrasonic measurements on increment cores. Holzforschung 55:606-610

Zhang SY, Morgenstern EK (1995) Genetic variation and inheritance of wood density in black spruce (Picea mariana) and its relationship with growth: implications for tree breeding. Wood Sci Technol 30: 63-75

Zhang SY, Koubaa A (2008) Softwoods of eastern Canada: their silvics, characteristics, manufacturing and end-uses. FPInnovationsForintek Division, Vancouver, British Colombia, SPEC. PUBL. SP-526E 